\title{
correspondence course
}




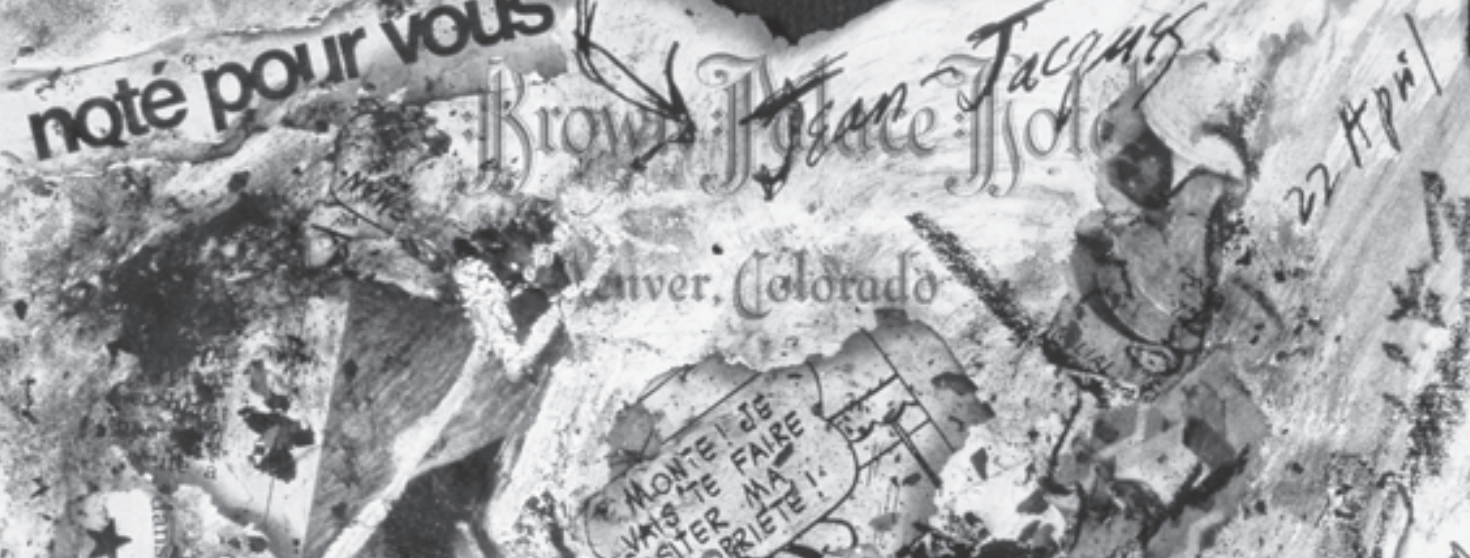

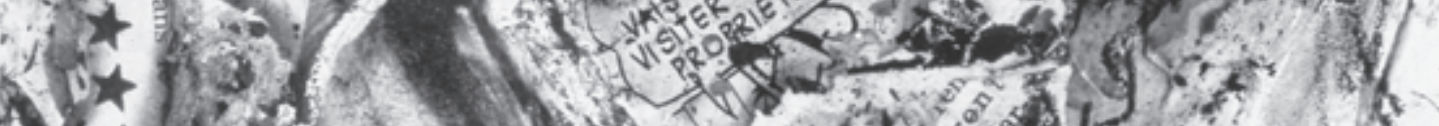

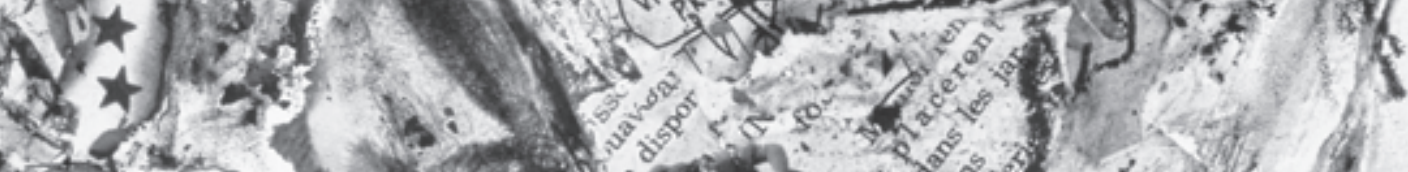

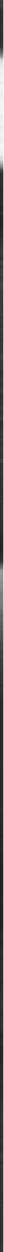

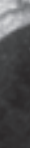

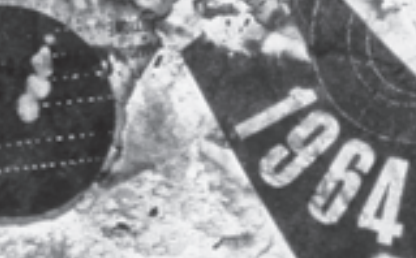

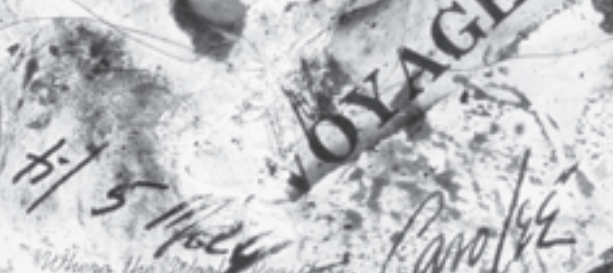


EPISTOLARY HISTORY OF

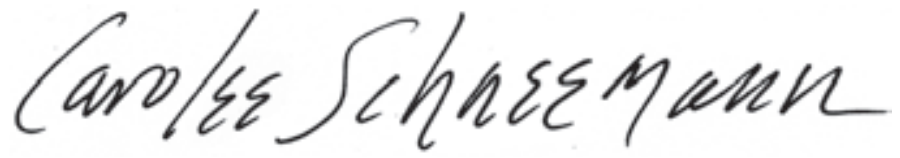

AND HER CIRCLE

\title{
Correspondence Course
}

\author{
EDITED BY
}

KRISTINE STILES

DUKE UNIVERSITY PRESS / DURHAM AND LONDON / 2010 
Introduction, notes, and edition (C) 2010 Duke University Press Copyrights to the letters remain with their authors All rights reserved. Printed in the United States of America on acid-free paper @ Designed by C. H. Westmoreland Typeset in Charis and Helvetica by Tseng Information Systems, Inc. Library of Congress Cataloging-in-Publication Data appear on the last printed page of this book.

Duke University Press gratefully acknowledges the support of the Millard Meiss Foundation and the Mary Duke Biddle Foundation for their support of this publication.

frontispiece: Carolee Schneemann letter to Jean-Jacques Lebel, 22 April 1964. Courtesy of Jean-Jacques Lebel Archive, Paris, and Carolee Schneemann. 